\title{
A IMPORTÂNCIA DO PLANEJAMENTO PARA INOVAÇÃO ANÁLISE DO GOVERNO LULA (2003-2010)
}

André Bologna de Castro Cardoso 1

\section{RESUMO}

O objetivo do artigo é, a partir de um referencial teórico sobre a importância do planejamento estatal para fomento da inovação, analisar se o governo Lula conseguiu utilizar ferramentas de planejamento econômico para fazer políticas industriais próinovação.

Palavras-chave: Políticas de inovação; Planejamento econômico; Governo Lula (2003- 2010).

\section{INTRODUÇÃO}

A inovação, entendida como um processo de criação de novas mercadorias, novos métodos de produção, novos mercados, novas formas de organização, dentre outros é o motor do capitalismo. (Schumpeter, 1982). É um processo de "destruição criativa”, na qual se destroem as estruturas anteriores para desenvolver novas que faz o capitalismo funcionar.

As transformações mundiais ocorridas no âmbito da tecnologia fizeram com que as políticas de inovação fossem muito mais focadas na interação entre os diversos agentes econômicos - empresas, universidades, institutos de pesquisa e Estado.

1 Mestrando do Programa de Pós-graduação em Economia Política da Pontifícia Universidade Católica (PUC) - São Paulo 
A incerteza e o risco de criar algo faz com que a interdependência entre diversos agentes da economia seja fundamental para se desenvolver um ambiente favorável à inovação. Para tanto, é necessária uma atuação forte do Estado para promover essa coordenação, seja atuando de maneira direta, através de universidades públicas, institutos nacionais e pesquisa e subsídios, ou indiretamente, ao promover um ambiente adequado para que as empresas inovem.

No Brasil, o planejamento estatal, entendido como atuação do Estado para coordenar programas e os diversos agentes, foi perdendo espaço a partir dos anos 1980 e 1990, diante de uma série de fatores, dentre os quais a hiperinflação e a liberalização da economia.

Diante desse quadro, governo Lula (2003-2010) buscou não só retomar o planejamento do Estado na condução das políticas de inovação, como intensificá-las, em vistas de trazer maior crescimento econômico, através do maior fomento tanto à ciência e tecnologia quanto à inovação.

Maior atuação do Estado na promoção da inovação não quer dizer que realmente haverá desenvolvimento adequado, pois, dependendo de como as medidas forem realizadas, os resultados podem não ser os melhores no sentido do desenvolvimento de um processo real de inovação, podendo ter impactos reduzidos na economia. Mais do que o simples planejamento estatal, é preciso compreender de que forma ele é realizado.

O objetivo do artigo é analisar se, durante o governo Lula (2003-2010), o Estado brasileiro conseguiu realizar esse importante papel como coordenador da política de inovação, de modo a integrar diversos agentes para expandir o processo inovativo na economia brasileira, e quais seus resultados. Para tanto, o artigo está dividido em quatro seções. Na primeira faz-se uma revisão teórica sobre política de inovação. $\mathrm{Na}$ segunda, trata-se das medidas adotadas pelos governos anteriores na década de 1990. Na terceira, descreve-se os programas adotadas pelo governo Lula e, por fim, na quarta seção há uma discussão de alguns resultados.

\section{POLÍTICA DE INOVAÇÃO E PLANEJAMENTO}

Suzigan e Furtado (2006), argumentam que há toda uma relação entre os diversos agentes da economia - Estado, empresas, centros de pesquisas, universidades. O planejamento do Estado em articular toda essa rede de agentes se faz necessário para que o processo de inovação se desenvolva e gere efeitos multiplicadores 
para a economia, direcionando a política para setores que consigam gerar mudanças tecnológicas para desenvolvimento de um sistema nacional de inovação, aumentando a competitividade e o desenvolvimento econômico.

A inovação é fruto de um sistema nacional ou regional, no qual a empresa está inserida. O importante não é o aumento dos gastos com Pesquisa e Desenvolvimento (P\&D) em si, mas na forma como seus resultados são distribuídos por toda a economia. (Mazzucato, 2014). O sistema de inovação é uma rede:

(...) formada por clientes, subcontratados, infraestrutura, fornecedores, competências ou funçōes e as ligaçōes ou relações entre eles. A questão é que as competências que geram inovação fazem parte de uma atividade coletiva que ocorre por meio de uma rede de atores de suas ligações ou relações. (ibid., p. 67)

É a difusão do conhecimento e da informação que permite às empresas continuamente inovar. Não é o ato individual da empresa levará ao aumento da inovação, ao contrário, é o ambiente em que ela está inserida que a permite inovar.

Como afirma Mazzucato (2014), a realização da inovação se dá diante de um cenário de grande incerteza. Inovar não é algo simples para uma empresa, visto que caso tal processo não for bem-sucedido, ela incorrerá em enormes prejuízos. Para mitigar a incerteza, a coordenação entre os diversos agentes é fundamental.

O planejamento econômico, dentro do campo da inovação, pode ser visto pelo conceito de sistema nacional de inovação, o qual é definido como unidade de instituiçôes que permitem desenvolver o aprendizado e a capacidade inovativa tanto de um país ou região.

(Cassiolato e Lastres, 2005).

Por outro lado, a ênfase à preservação e promoção da diversidade e a importância atribuída à cooperação conferem ao Estado importante papel de coordenador das necessárias políticas descentralizadas - isso tudo dentro de um projeto de desenvolvimento de longo prazo para o país. (Cassiolato e Lastres, 2005, p. X)

O papel do Estado na inovação ganha um papel de extrema relevância, pois ele deve mobilizar recursos de modo que o conhecimento possa se dissipar por toda a sociedade. (Mazzucato, 2014). Sem a atuação do Estado, a incerteza e os custos muitas vezes elevados fazem com que muitas inovações sejam desestimuladas (Brandão e Drummond, 2012).

A empresa privada é o ente responsável pela inovação, porém, suas estratégias dependem do ambiente competitivo, no qual ela está inserida, o que pode impor limites às suas ações. A atuação do Estado, através do planejamento, altera esse 
ambiente institucional e competitivo, dando maiores incentivos para elas realizarem suas estratégias de inovação. (Gadelha, 2001)

Dois elementos ${ }^{2}$ propostos por Rodrik (2004) são de extrema importância para uma política de inovação: a primeira é a política industrial (ou de inovação) deve estar voltada para atividades novas, e, portanto, em segundo lugar, o Estado não deve eleger setores específicos, mas, sim, atividade chaves. Isso porque, ao realizar políticas mais transversais, o conhecimento e informação tendem a se dissipar mais e atingir um número muito maior de setores do que um investimento em um setor específico.

As concepçôes lineares de política econômica e o estabelecimento preciso de relações de causa e efeito entre a intervenção pública localizada e direta e as estratégias privadas devem ser superadas em favor de um padrão de intervenção mais indireto que privilegie a criação de condições ambientais favoráveis às estratégias empresariais de inovação. (Gadelha, 2001, p. 156)

Ressalta-se necessidade de instituições adequadas de fomento à inovação tanto público quanto privadas. As primeiras devem coordenar e executar determinadas políticas, e as segundas deveriam se organizar em entidades representativas e em grupos de interesse. Novamente, a coordenação entre instituições públicas e privadas são essenciais para política de inovação.

As novas políticas de inovação, como afirmam Cassiolato e Lastres (2005), devem estar focadas não só na pesquisa e desenvolvimento, como na cooperação e expansão de pesquisas no longo prazo. A política deve realizar:

(...) estímulo à formação de novas instituições e organizações de natureza coletiva, e da implementação de açôes que estimulam as empresas e demais atores locais a interagirem. Além dos projetos de pesquisa e desenvolvimento conjuntos, tais açóes têm incluído a formação e capacitação de recursos humanos, informação, design etc. (Cassiolato e Lastres, 2005, p. 39-40)

No Brasil, Pacheco e Almeida (2013) ressaltam as dificuldades da política de inovação. A pesquisa e desenvolvimento estariam muito ligados à área acadêmica, sem transposição para as empresas. Além do mais, há pouco enfoque das empresas para competição externa, fazendo com que haja poucos incentivos para inovar. Por fim, as dificuldades macroeconômicas associadas com infraestrutura deficitária em relação ao que se deveria ter e a falta de mão-de-obra qualificada ampliam o quadro de obstáculos a serem enfrentados.

2 Esse autor cita 10 elementos, porém, para o propósito desse texto, vamos elencar dois que achamos principais para objetivo do texto. Para maiores detalhes ver Rodrik (2004) 


\subsection{Inovação na década de $\mathbf{1 9 9 0}$}

Para entender a própria política de inovação no governo Lula, é preciso compreender os antecedentes. Desde os anos 1980, segundo Motoyama (2005), com a hiperinflação e baixo crescimento econômico a política de inovação e tecnológica no Brasil sofreu fortemente, ainda que, no governo Sarney (1986-1989) tenha sido criado o Ministério da Ciência e Tecnologia (MCT), o cenário era desolador. Com a entrada do governo Collor (1990-1992) esse cenário piorou ainda mais, pois este quase acabou com o potencial tecnológico do Brasil.

Diante da visão de que a economia brasileira precisava se abrir e se modernizar, através da liberalização econômica, o objetivo era atrair o investimento externo e criar um cenário institucional que privilegiasse o mercado, e não a cooperação entre diversos agentes. (Lemos e Cários, 2013). O governo Collor buscou reduzir a participação do Estado na economia. Os gastos públicos com $\mathrm{P} \& \mathrm{D}$ foram reduzidos para $0,4 \%$ do PIB, além de que o MCT foi transformado em mera Secretaria de Ciência em Tecnologia. (Motoyama, 2004)

O governo intermediário de Itamar Franco (1993-1994) não trouxe grandes avanços para inovação, mas não a deixou de lado. O MCT foi restabelecido e concederam-se incentivos fiscais, reintroduzindo os subsídios fiscais como fonte de financiamento para ciência e tecnologia, que haviam sido desmontadas no governo anterior (Lemos e Cário, 2013).

O governo Fernando Henrique Cardoso (1995-2002) pode ser dividido em duas partes quanto à política de inovação. No período que vai de 1995-1998, o foco estava em uma visão de que a ciência e tecnologia se tornariam mais competitivas com a estabilidade econômica (Montoyama, 2004).

Mas mais importante foi a Reforma do Estado, em que houve reformulações na estrutura estatal, em vistas de torná-lo mais eficiente, por meio de privatizações, assim como aumento das restriçóes para empresas estatais, institutos de pesquisa e universidades, com redução dos recursos destinados a elas. O principal instrumento de política de inovação foi o Plano Plurianual (PPA) em que se incluía ciência e tecnologia, além do lançamento do programa de Apoio a Núcleos de Excelência (PRONEX), visando apoiar pesquisadores reconhecidos em suas áreas de atuação para incentivar a pesquisa tecnológica o país. (Lemos e Cário, 2013)

Não houve mudanças estrutural na política de inovação e tecnológica no Brasil, salvo algumas leis de incentivos como Lei de Propriedade Industrial, por exemplo, (ibid), mas que não tiveram impactos para retomada de políticas de inovação, as quais estavam fora de qualquer projeto de governo. 
Já no segundo governo Fernando Henrique Cardoso, que vai de 1999-2002, a situação muda completamente e a política de inovação começa a ganhar um peso mais importante dentro da estratégia governamental. Segundo Montoyama (2004), o MCT envolve-se em apoio de áreas de fomento de investimento, como nas áreas de biotecnologia, tecnologias da informação e dentre outros setores importantes. Segundo esse autor, buscaram-se novas institucionalidades jurídicas, contudo, o principal incentivo à inovação veio da criação de fundos setoriais (FS).

A criação dos FS representou uma inovação institucional no financiamento das atividades de C\&T no Brasil, trazendo grande expectativa em relação à escala e estabilidade dos investimentos na área, permitindo a reorientação da agenda do fomento no suporte à inovação empresarial e ainda consolidando um fluxo regular de recursos para a pesquisa científica, constituindo-se num modelo de convergência entre a política industrial e as políticas de C\&T. (Lemos e Cário, 2013, p. 12)

Os recursos advindos para os fundos advêm de vários impostos, como parte de Impostos sobre Produtos Industrializados (IPI) de certos setores e Contribuição de Intervenção no Domínio Econômico (CIDE). Mais importante do que os recursos advindos, é a forma como se estruturam os fundos setoriais. Segundo Gomes et al., (2015), o dinheiro é canalizado para Fundo Nacional de Desenvolvimento Científico e tecnológico (FNDCT) e é administrado pelo FINEP. Cada fundo é gerido é por um representante do MCTI, sendo que cada comitê gestor tem representantes de diversas áreas, como ministérios, universidades, empresas e outras agências.

Segundo Lemos e Cário (2013), com ajuda dos fundos setoriais, a política de inovação nessa segunda fase de Fernando Henrique Cardoso, houve maior cooperação entre empresas, fomentando novas atividades inovativas e ampliando a infraestrutura da ciência e tecnologia.

\subsection{Governo Lula (2003-2010)}

A primeira política adotada pelo governo Lula, em 2003, foi a Política Industrial, Tecnológica e de Comércio Exterior (PITCE), cujo enfoque era uma ação industrial voltada para inovação. As diretrizes do plano, segundo Araújo (2012, p. 11) foram:

1) Inovação dentro das empresas, ou seja, as empresas deveriam ter um papel mais relevante na inovação. 2) Aumento das exportaçôes de alta tecnologia. 3) Atualizações e modernização industrial. 4) Aumento da escala de produção. 5) Desenvolver campos de pesquisa selecionados.

A PITCE seguiu três eixos fundamentais, sendo o primeiro de linhas horizontais, como desenvolvimento tecnológico, institucional e de comércio exterior. Já a segunda linha referia-se a setores estratégicos, focando nos que utilizam tecnologia 
mais avançada, como softwares, bens de capital e semicondutores. E por fim, em atividades que visam o futuro, tais como biotecnologia e nanotecnologia (Brandão e Drummond, 2012).

O principal objetivo da PITCE era constituir uma base produtiva industrial forte, por meio de maior eficiência e disseminação tecnológica pela economia com intuito de crescer internamente e competir externamente. (Cardoso Jr e Gimenez, 2011). Os setores mais beneficiados pela PITCE foram bens de capital, softwares e semicondutores, cujo desenvolvimento tende a elevar a produtividade e os efeitos positivos para a estrutura industrial. (Kupfer, 2013)

Para atingir esse objetivo, precisava-se avançar na coordenação de um sistema nacional de inovação, em que institucionalidades e bases legais deveriam ser definidas de modo a articular os agentes envolvidos nesse processo. Acabou-se focando em setores mais intensivos em conhecimento e que pudessem gerar maior dinamismo. (Cardoso Jr. e Gimenez, 2011)

Araújo (2012) afirma que a PITCE trouxe duas importantes contribuições para a inovação: a Lei de Inovação (2004) e a Lei do Bem (2005). A primeira criou um ambiente regulatório favorável à cooperação entre empresas-universidade, permitindo alianças importantes para se avançar na questão da inovação:

A Lei da Inovação está organizada em torno de três eixos: a constituição de um ambiente propício à construção de parcerias entre as universidades, institutos tecnológicos e empresas, o estímulo à participação de instituições de ciência e tecnologia no processo de inovação; e o incentivo direto à inovação na empresa. (Lemos e Cário, 2013, p. 14)

A Lei da Inovação buscou criar um ambiente jurídico institucional adequado para que houvesse maior coordenação entre os diversos agentes da economia. $\mathrm{O}$ governo ampliou as possibilidades de se desenvolver um Sistema Nacional de Inovação, via planejamento governamental, levando em conta a interdependência dos agentes. De outro lado, a Lei do Bem foi importante como forma de financiar a ciência e tecnologia no país.

A mudança de cenário internacional com a valorização do preço das commodities fez com que o real se valorizasse, dificultando as exportações de produtos de maior conteúdo tecnológico. Assim, o principal resultado da PITCE foi a melhoria do aparato institucional para desenvolvimento da inovação. (Kupfer, 2013)

Em 2008, o governo adota outra política: Política de Desenvolvimento Produtivo (PDP), a qual incluiu mais setores favorecidos pela política anterior. Os objetivos eram: 1) aumento do investimento fixo para $21 \%$ do PIB; 2 ) ampliar as exportações brasileiras para $1,25 \%$ do total mundial; 3 ) elevar o gasto com pesquisa 
e desenvolvimento para 0,65\% PIB; 4) aumentar em 10\% médias e pequenas empresas exportadoras. Para isso, utilizar-se-ia instrumentos de incentivos - crédito e financiamento estatal -, compras do governo, instrumentos de regulação e apoio técnico (Cardoso Jr e Gimenez, 2011).

O foco setorial pode ser demonstrado nas estratégias defensivas. Kupfer (2013) afirma que objetivo da PDP se voltou para incentivar a expansão do investimento, dado o cenário favorável da economia interna. Buscou-se abranger vinte e cinco setores que poderiam ser líderes mundiais de modo a receberem incentivos de fortalecimento de competitividade. Porém, o cenário externo acabou sendo desfavorável com a crise de 2008. PDP teve um papel muito mais anticíclico do que de fomentar a inovação. $\mathrm{O}$ resultado foi que as empresas mais se defenderam do que realmente criaram.

Cardoso Jr e Gimenez (2011) contrastam a PDP da PITICE no sentido de que a segunda se voltou mais para superar a estagnação industrial vinda dos anos 1990, enquanto a primeira buscava sustentar o crescimento econômico no longo prazo, ao tentar ampliar a capacidade de oferta, manter o balanço de pagamento robusto, e, por fim, elevar capacidade de inovar das empresas nacionais.

De qualquer modo, segundo esses autores, os dois planos conseguiram colocar em pauta novamente a ação do Estado no planejamento em uma área tão importante para o desenvolvimento econômico nacional. Mas salientam que se na PITCE, os objetivos e estratégias tinham um elemento mais genérico de política de inovação, a PDP teve como ponto o pragmatismo.

Para os anos correspondentes a 2007-2010, outro plano foi lançado: Plano de Ação em Ciência, Tecnologia e Inovação (PACTI), que, segundo Araújo (2012), tinha como metas: 1) estruturação do Sibratec, chamada "rede das redes" existentes de instituições de pesquisa para apoiar o desenvolvimento tecnológico; 2) aumentar número de pesquisadores trabalhando em empresas (para 33,5\%), mas que não se concretizou; 3) aumento da proporção de empresas inovadoras que recebem ajuda do governo (para 24\%) o que aconteceu. 4) Investimentos na ordem de $\mathrm{R} \$ 36$ bilhões no período.

No financiamento da inovação, Avellar (2010) afirma que os principais instrumentos de política de inovação no Brasil são os incentivos fiscais e financeiros. Ela diferencia dois modelos de incentivos: primeiro, o direcionamento de recursos para determinados setores e projetos específicos, dando ao Estado poder de definir estratégias de desenvolvimento tecnológico. Já o segundo, os benefícios fiscais permitem às empresas maior liberdade de investir como e onde seus recursos no polo da inovação. 
Segundo essa autora, os incentivos financeiros são concedidos pelo BNDES e pelo FINEP, cujas linhas de financiamento principais são o Programa de Desenvolvimento de Inovação, substituído pela Inovação Tecnológica em 2008, e Inova Brasil e Juro Zero, respectivamente. Inova Brasil criou três grandes de categorias de projetos - mobilizadores em áreas estratégicas, conciliar e expandir liderança, e fortalecimento da competitividade - com taxas fixas entre $4 \%$ a $8 \%$, enquanto o programa Juro Zero procura reduzir os encargos financeiros e burocracia para permitir que pequenas e médias empresas possam ter condições de investir mais em inovação. (Avellar, 2010)

Os programas do BNDES, tanto o Programa de Desenvolvimento de Inovação (2006) quanto o Inovação Tecnológica (2008), destinam recursos para financiar projetos de desenvolvimento em inovação com valor superior a $\mathrm{R}$ \$ 1 Milhão, os quais tenham riscos tecnológicos altos e oportunidade de mercado para criar produtos e novos processo. Importante ressaltar que nessas linhas não há necessidade de terceiros, sendo feitos diretamente com o banco. (Avellar, 2010)

Um dos programas mais efetivos é o Programa de Subvenção Econômica (2008), cuja ideia é utilizar recursos públicos direto nas empresas, sem necessidade de devolução. Feito pela Finep, esse programa se realiza por chamadas públicas, definindo valores mínimos, contrapartidas, temas e áreas selecionadas. Outra linha utilizada pela Finep é Programa Primeira Empresa Inovadora (criado em 2008), cujo foco é dar condições financeiras para empresas nascentes que podem gerar alto valor agregado. (Avellar, 2010)

O Fundo Tecnológico (Funtec) aplicado pelo BNDES, também, procura financiar empresas que se relacionam com outras instituições associadas à inovação (Araújo, 2012). E relacionada com a área de pesquisa, a Finep opera um programa de subvenções para contratação de pesquisadores por parte das empresas. (Avellar, 2010)

Por fim, Avellar (2010) e Araújo (2012) definem os instrumentos fiscais utilizados para desenvolvimento tecnológico: redução de imposto de renda e crédito fiscal. Este tipo de financiamento se tornou um dos principais elementos para incentivar a inovação. A Lei do Bem, como já dito, permitiu conceder maiores benefícios fiscais, os quais se tornaram automáticos, de modo que as empresas não precisarem projeto prévio antes de receberem os incentivos.

Pela Lei do Bem há inúmeros benefícios fiscais, tais como dedução do Imposto de Renda Pessoa Jurídica (IRPJ) e da Contribuição Social do Lucro Líquido (CSLL) para gastos com pesquisa e desenvolvimento, além de redução em 50\% do Imposto sobre Produtos Industrializados (IPI) para compras de bens de capital relacionados com a inovação, dentre outras. (Araújo, 2012) 
-• Economia Brasileira em Debate

\section{RESULTADOS}

Para analisar os resultados obtidos na inovação durante o governo Lula utilizar-se-á os relatórios da PINTEC para os períodos de 2003-2005, 2006-2008 e 2009-2011. Pode-se distinguir dois períodos: entre 2003-2008 e 2009-2011, sendo o último período em que vigorou a PDP. No primeiro observou-se crescimento e desenvolvimento intenso da inovação, enquanto no segundo os resultados não foram tão satisfatórios.

No gráfico 1, pode-se observar o percentual de empresas que realmente implementaram inovações no Brasil. Houve crescimento, ainda que não muito expressivo, durante período se comparado com início do governo, ainda que se tenha observado queda em 2009-2011 em relação a 2006-2008. Isso indica que as políticas de inovação conseguiram algum sucesso, ainda que não tenha sido suficiente para se sustentar por todo período.

Gráfico 1 Empresas que implementaram inovação no total (\%) - Brasil, 1998-2011.

45

40

35

30

25

20

15

10

5

0

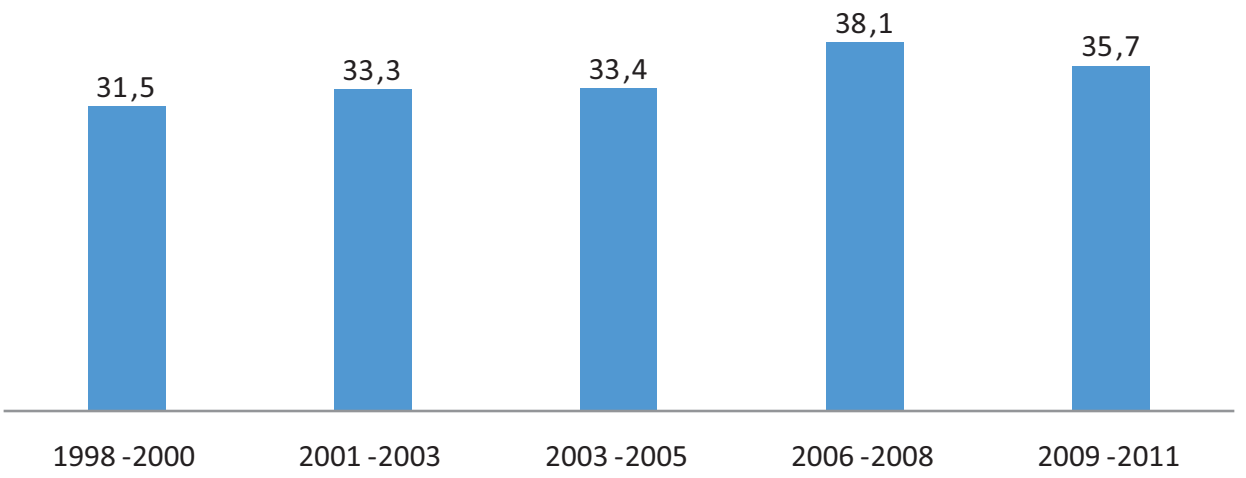

Fonte: Elaboração própria a partir dos relatórios da PINTEC $(2003,2005,2008,2011)$

No Gráfico 2, percebe-se que a relação $\mathrm{P} \& \mathrm{D} / \mathrm{PIB}$ aumentou no Brasil, nesse período, saindo de 0,97\% em 2002 para 1,15\% em 2010. Se comparado com um país em desenvolvimento, como a Rússia, o Brasil está bem situado, porém muito aquém da China, a qual aumentou fortemente seus gastos em inovação. Na comparação com países desenvolvidos, a situação brasileira não é nada favorável, indicando que os gastos com P\&D estão bem abaixo. Tomando a média mundial de $2 \%$, a situação brasileira, apesar de ter evoluído nos últimos anos, está longe de um padrão adequado de inovação. 
Gráfico 2 Gastos com P\&D sobre PIB (\%) - Países selecionados, 2002-2010.

3,5

3

2,5

2

1,5

1

0,5

0

$-1-2-3-4-5-6-7-7-8-9$ Brazil China Russia União Europeia Coreia do Sul

Fonte: Elaboração própria a partir dos relatórios do Banco Mundial

Por outro lado, ressalta-se que a cooperação entre empresas e outras organizações aumentaram no período, saindo de $11 \%$ do total das empresas que inovaram em 1998-2000 para 15,9\%, no início de 2009-2011, indicando que os planos do governo Lula tiveram essa preocupação em fomentar a interação entre os diversos agentes da economia.

A formação dos Fundos Setoriais, juntamente, com o arcabouço institucional da Lei de Inovação induziu maior cooperação entre os diversos agentes na economia, principalmente, a partir do governo Lula.

Gráfico 3 Participação das empresas com relações de cooperação com outras organizações (\%) - Brasil, 2001-2011.

18

16

14

12

10

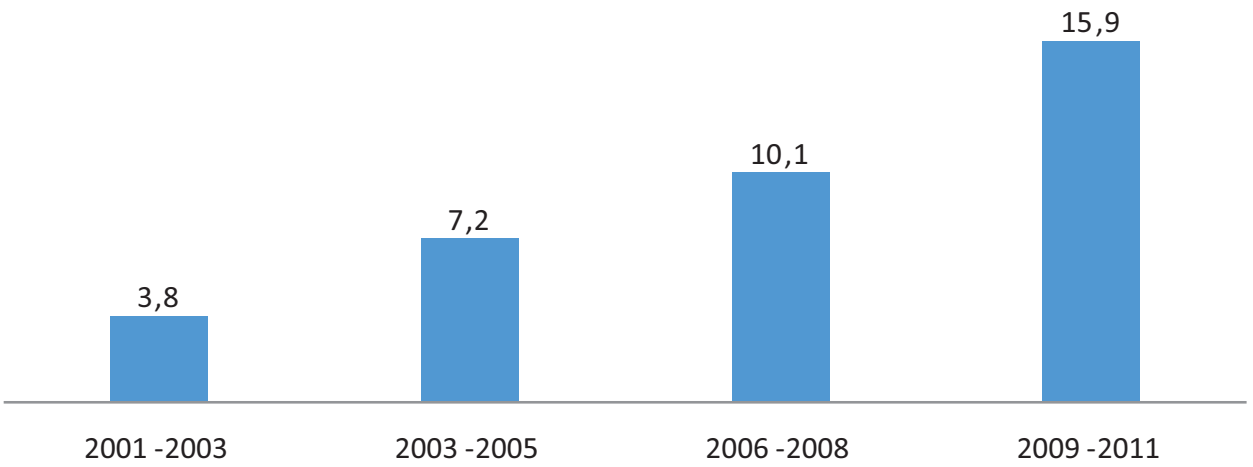

Fonte: Elaboração própria a partir dos relatórios da PINTEC $(2003,2005,2008,2011)$ 
Contudo, é necessário olhar quais os tipos de gastos com inovação que as empresas realizaram. O que se vê no gráfico 3 é justamente que os maiores dispêndios das empresas que realizaram inovação continuam sendo com a compra de máquinas e equipamentos, enquanto que atividade em P\&D e introdução de novos produtos no mercado ainda são relativamente pequenos. "O maior crescimento da inovação em processos para as empresas sinaliza muito mais a incorporação de novas máquinas ao parque produtivo, que foi e continua sendo a principal forma de inovação das firmas no Brasil.” (Almeida, 2011, p. 77)

Gráfico 4 Percentual da receita líquida gasta com atividades inovativas (\%) - Brasil, 1998-2011.

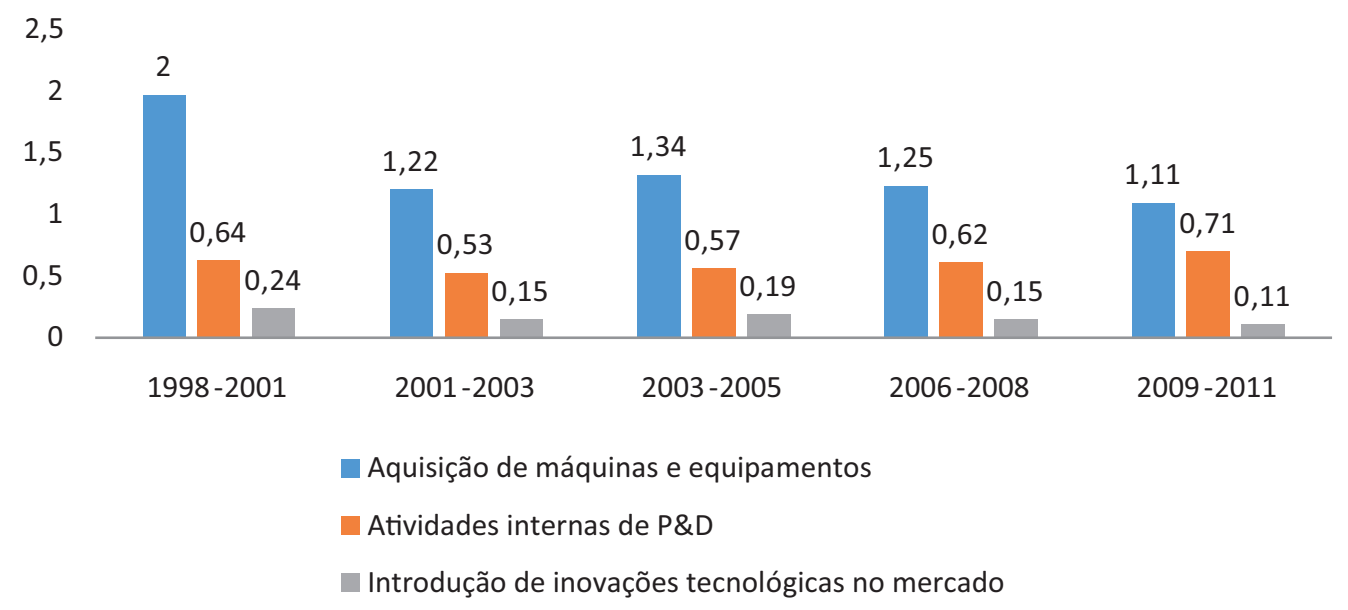

Fonte: Elaboração própria a partir dos relatórios da PINTEC $(2003,2005,2008,2011)$

No gráfico 4, nota-se que por mais que tenha havido avanços para criação de novos mercados e para própria ampliação da gama de produtos, o maior impacto da inovação reside em manutenção da participação do mercado, demonstrando que as empresas utilizam a inovação para defenderem da concorrência, trazendo impactos reduzidos para disseminação de conhecimento e inovação para toda a economia. A inovação serviu muito mais para conservar do que para realmente criar e desenvolver. 
Gráfico 5 Impactos mais relevantes da inovação, segundo as empresas (\%) - Brasil, 1998-2011.

100

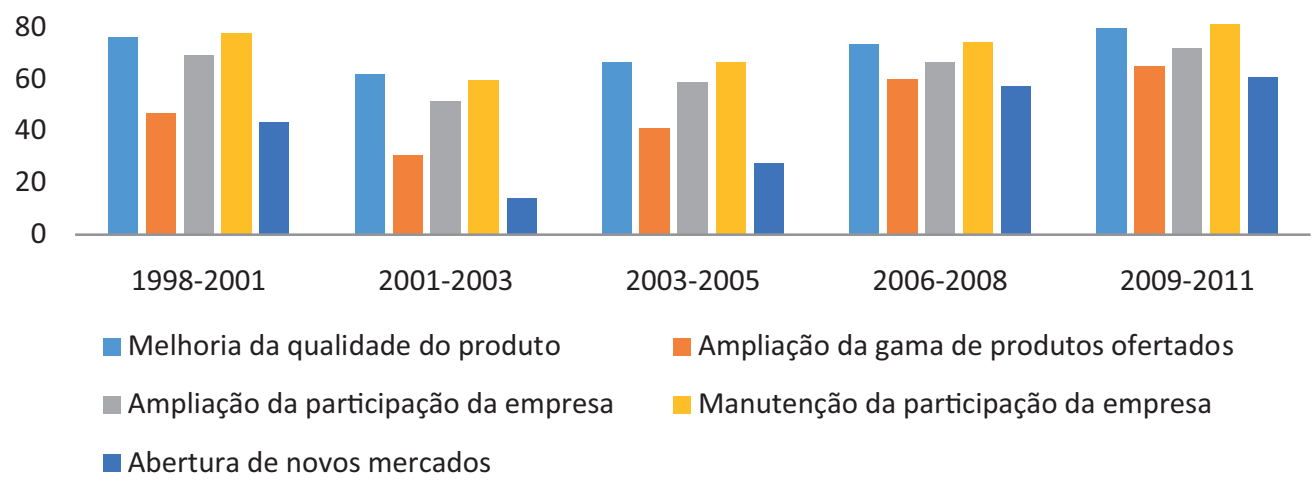

Fonte: Elaboração própria a partir dos relatórios da PINTEC (2003, 2005, 2008, 2011)

Apesar dos planos executados no governo Lula tenham tentado retomar o planejamento econômico no âmbito de desenvolver um sistema nacional de inovação, não se pode dizer que resultados tenham sido conquistados. Isso porque, segundo Brandão e Drummond (2012), os programas adotados não criaram atividades novas. Ao invés da política ter gerados efeitos de transmissão da inovação para vários setores, eles focaram apenas naqueles setores já tradicionais.

Um dos elementos fundamentais à PI pró-inovação diz respeito ao governo provocar aprendizados tecnológicos a partir do fomento às atividades inovativas, independentemente da departamentalização da indústria, enquanto que a PI adotada na "Era Lula" tem foco setorial. (Ibid., p. 11)

A PITCE, segundo Almeida (2011) teve um caráter generalista, sem muita clareza e que acabou focando em setores que o Brasil já tem consideráveis vantagens comparativas. Além do mais, as metas da PDP eram de curto prazo, servindo muito mais como elemento eleitoral do que mudanças estruturais que são de longo prazo.

Dentro do PDP, a meta para 2010 era que o investimento em pesquisa e desenvolvimento subisse para $0,65 \%$ do PIB, porém, efetivamente foi de $0,59 \% \mathrm{em}$ 2010. Comparado ao período de 2006-2008, entre 2009-2011, o percentual de empresas inovativas decaiu, como pode ser visto no gráfico 1, ainda que se possa ver uma evolução desde 2000.

Segundo Brandão e Drummond (2012), as justificativas para as metas não terem sido alcançadas foram a crise mundial de 2008, e de que muitas empresas teriam mudado de pequenas para médias empresas. Contudo, observando o desenho 
da política adotada percebe-se que as medidas adotadas não foram suficientes para fazer com que o processo inovativo se expandisse no Brasil, como se esperava.

No âmbito do financiamento, segundo dados do próprio relatório da Pintec para o ano de 2011, houve um aumento exponencial de empresas que, pela lei do Bem, utilizaram recursos fiscais e subvençôes para suas atividades, saltando de 440 empresas no período entre 2006-2008 para 1.044 em 2009-2011. Contudo, nota-se que a maior fonte de financiamento dos projetos de inovação são os recursos internos às empresas, o que traz limites à inovação, visto que as empresas podem se tornar mais conservadoras em investir em atividades mais arriscadas.

Brandão e Drummond (2012) mostram que a maior parte dos recursos do BNDES, quase $75 \%$, foram destinados para programas setoriais. Segundo eles, esses recursos, tanto do BNDES quanto fiscais, se voltaram para setores, em que o Brasil ou já tem vantagens comparativas (como agropecuária, mineração) ou para aqueles, como Aeronáutica e Petróleo, em que as possibilidades de financiamento próprio são mais fáceis do que em setores mais arriscados.

É possível afirmar que, com ou sem política industrial, o perfil dos empréstimos do BNDES não seria muito diferente do que foi nos últimos anos. O que se destaca na política industrial do Brasil é muito mais o aumento da oferta de crédito subsidiado do que o fomento à descoberta de novos processos de produção e/ou atividades (...) (Almeida, 2011, p. 76).

Os resultados e sua análise indicam que houve avanços na política de inovação no período recente. Contudo, a inovação realizada ainda não está voltada para real criação de produtos e processos novos que permitam mudar a estrutura industrial brasileira, pois tanto os recursos como os próprios impactos da tecnologia são destinadas às empresas e setores, nos quais o Brasil já é forte e não para atividades novas. A própria inovação tem servido muito mais para manutenção de participação de mercado do que para mudanças profundas.

\section{CONCLUSÃO}

O intuito de uma política de inovação é modificar a estrutura existente para uma que crie produtos e processos novos, tanto para melhorar a competitividade interna quanto externa. Deve-se adotar mecanismos que estimulem a busca do novo, do mais arriscado, porém, como isso envolve riscos e incerteza, é o planejamento do Estado que permite mitigar as dificuldades e permitir que diversos agentes possam atuar em conjunto. 
Entre as décadas de 1980 e 1990, o potencial tecnológico brasileiro foi deixado de lado. Não houve mudanças estruturais, como, ao contrário, houve retrocessos. Somente a partir de 1999 é que o Estado, através dos fundos setoriais, começou a ter, ainda que lentamente, papel decisivo para realizar política de inovação.

Com o governo Lula, em 2003, os planos impostos buscaram trazer o planejamento governamental, não apenas na atuação direta, quanto na tentativa de coordenar os vários agentes envolvidos na questão da inovação. Os objetivos estavam voltados para uma maior relação entre universidades, instituições de pesquisa e empresas para fomentar inovação para geração de valor e melhorar a inserção externa, ao mesmo tempo, em que se utilizou de financiamentos, principalmente, via desoneração fiscal para reduzir custos e riscos para que as empresas pudessem inovar.

De outro lado, Kupfer (2013) afirma que dez anos para realização de uma política industrial e de inovação é pouco para mudanças estruturais. A própria política industrial se subordinou à política macroeconômica, o que não permitiu à primeira ter um espaço de autônomo.

Cardoso Jr e Gimenez (2011) apontam dificuldades e contradições macroeconômicas como obstáculos ao aprofundamento da estrutura industrial. $\mathrm{O}$ câmbio valorizado, falta de infraestrutura e juros altos desestimulam investimentos na área.

Não se pode indicar que foram apenas desequilíbrios macroeconômicos e falta de um horizonte maior como responsáveis pelos obstáculos às mudanças. $\mathrm{O}$ próprio desenho dos programas, por mais que tivessem elementos importantes para aumentar a inovação, acabaram sendo muito mais voltados para setores, em que tradicionalmente, o Brasil já era forte do que realmente criar e desenvolver novos. A inovação nas empresas foi muito mais voltada para compra de máquinas e equipamentos, para conseguirem manter suas participações no mercado, do que para criar coisas novas. $\mathrm{O}$ foco setorial, ao invés de criar um ambiente em que novos setores e empresas pudessem surgir, só intensificou a estrutura existente.

\section{REFERÊNCIAS}

ALMEIDA, Mansueto. O novo Estado desenvolvimentista e o governo Lula. Economia \& Tecnologia - Ano 07, Volume Especial - 2011.

ARAÚJO, Bruno César. Políticas de apoio à inovação: uma análise de sua evolução recente. IPEA: Texto para discussão. ago. 2012.

AVELLAR, Ana Paula. Políticas de Inovação no Brasil: uma análise com base na PINTEC 2008. Economia e Tecnologia. Ano 06, V. 23. out./dez., 2010. 
BRANDÃO, Leidiane Âlcantara; DRUMMOND, Carlos Eduardo Iwai. Políticas PróInovação: uma análise da política industrial nos oitos anos do governo Lula. Revista Economia \& Tecnologia (RET) V. 8 (2), p. 20-40, abr./jun. 2012.

CARDOSO JR, José Celso; GIMENEZ, Denis Maracci. Crescimento Econômico e Planejamento no Brasil (2003-2010): evidências e possibilidades do ciclo recente. In: CARDOSO JR, José Celso (Org.). Reinvenção do Planejamento governamental no Brasil. Brasília, Ipea, 2011.

CASSIOLATO, José Eduardo; LASTRES, Helena Maria Martins. Sistemas de Inovação e Desenvolvimento: as implicações de política. São Paulo em Perspectiva, v. 19, n. 1, p. 34-45, jan./mar. 2005.

GOMES, Vanessa Cabral et al. Os fundos setoriais e a redefinição do modelo de promoção da ciência, tecnologia e inovação no Brasil: uma análise a partir do CT-Agro. R. Adm., São Paulo, v. 50, n. 3, p. 353-368, jul./ago./set. 2015.

KUPFER, David. Dez anos de política industrial. Valor Econômico, 2013. Disponível em: http://www.ie.ufrj.br/clipping/download/dezanos.pdf. Acesso em: 18/04/2017.

LEMOS, Dannyela da Cunha; CÁRIO, Silvo Antonio Ferraz. A Evolução das Políticas de Ciência e Tecnologia no Brasil e a Incorporação da Inovação. Conferência Internacional LALICS 2013 "Sistemas Nacionais de Inovação e Políticas de CTI para um Desenvolvimento Inclusivo e Sustentável” 11 e 12 de novembro, 2013 - Rio de Janeiro, Brasil.

MAZZUCATO, Mariana. O Estado Empreendedor. São Paulo: Portfólio Penguin, 2012.

MOTOYAMA, S. (Org.) Prelúdio para uma história: ciência e tecnologia no Brasil. São Paulo: EDUSP, 2004.

PACHECO, Carlos Américo; ALMEIDA, Julio Gomes. A política de inovação. Texto para discussão. Instituto de Economia Unicamp, maio, 2013.

RODRIK, Dani. (2004). Industrial policy for thetwenty-first century. URL [on-line]: https://www.sss.ias.edu/files/pdfs/Rodrik/Research/industrial-policy-twentyfirstcentury.pdf. Acesso em: 18/04/2017.

SUZIGAN, Wilson; FURTADO, João. Política Industrial e Desenvolvimento. Revista de Economia Política, n. 26 (2), 2006. 